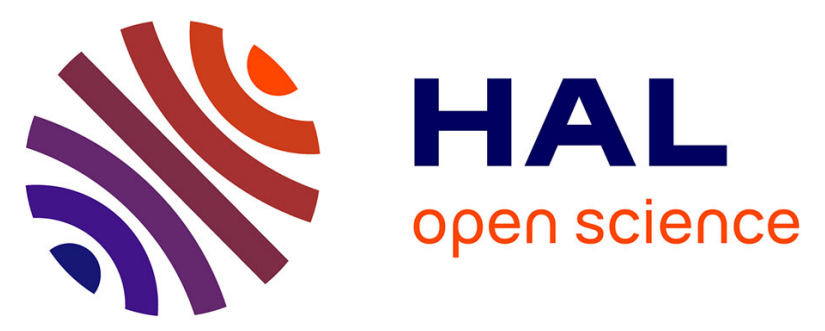

\title{
Role of surface energy and surface reconstructions on the 2D-to-3D growth-mode transition of strained In $\mathrm{x}$ Ga 1-x As layers on $\operatorname{InP}(001)$
}

Michel Gendry, G. Grenet, Y. Robach, P Krapf, L. Porte, G. Hollinger

\section{- To cite this version:}

Michel Gendry, G. Grenet, Y. Robach, P Krapf, L. Porte, et al.. Role of surface energy and surface reconstructions on the 2D-to-3D growth-mode transition of strained In x Ga 1-x As layers on $\operatorname{InP}(001)$. Physical Review B: Condensed Matter and Materials Physics (1998-2015), 1997, 56 (15), pp.9271-9274. 10.1103/PhysRevB.56.9271 . hal-02195176

\section{HAL Id: hal-02195176 https://hal.science/hal-02195176}

Submitted on 26 Jul 2019

HAL is a multi-disciplinary open access archive for the deposit and dissemination of scientific research documents, whether they are published or not. The documents may come from teaching and research institutions in France or abroad, or from public or private research centers.
L'archive ouverte pluridisciplinaire HAL, est destinée au dépôt et à la diffusion de documents scientifiques de niveau recherche, publiés ou non, émanant des établissements d'enseignement et de recherche français ou étrangers, des laboratoires publics ou privés. 


\title{
Role of surface energy and surface reconstructions on the 2D-to-3D growth-mode transition of strained $\operatorname{In}_{x} \mathrm{Ga}_{1-x}$ As layers on $\operatorname{InP}(001)$
}

\author{
M. Gendry, G. Grenet, Y. Robach, P. Krapf, L. Porte, and G. Hollinger \\ Ecole Centrale de Lyon, Laboratoire d'électronique, LEAME, UMR-CNRS 5512, F-69131 Ecully Cedex, France
}

(Received 25 November 1996)

\begin{abstract}
We show that the role played by surface energy in the total-energy balance between the initial twodimensional (2D) state and the final three-dimensional (3D) state is of prime importance to explain morphologies observed during the molecular-beam epitaxy growth of strained materials. This was established by analyzing differences in 2D-3D transition onsets for $2 \%$ mismatched $\operatorname{In}_{x} \mathrm{Ga}_{1-x} \mathrm{As}$ films grown on $\operatorname{InP}(001)$ substrates when changing the mismatch sign (compression or tension), the film doping, and the type of surface stabilization (anion or cation). The 2D-3D onsets were measured by reflection high-energy electron diffraction and the corresponding surface morphologies characterized by scanning tunneling microscopy. [S0163-1829(97)06439-4]
\end{abstract}

It is now well established that highly mismatched $(>2 \%)$ heteroepitaxy can evolve from a two-dimensional (2D) to a three-dimensional (3D) growth mode before the occurrence of plastic relaxation. Previous experiments ${ }^{1-3}$ and models ${ }^{4-6}$ revealed that the main parameters controlling the 2D-3D growth mode transition are elastic strain, surface energy, and surface diffusion kinetic. The classical view to explain the 2D-3D growth mode transition is that strained films grow first uniformly and commensurably with the strain energy increasing linearly with thickness up to a critical threshold beyond which it is energetically favorable to form a 3D morphology because of the reduction of the strain energy.

The present work aims to show that surface energy can be, in some cases, the predominant parameter controlling the surface morphology of strained layers and consequently the growth mode. As already emphasized by Tersoff ${ }^{7}$ about experiments by Xie et al. ${ }^{8}$ on $\mathrm{Ge}_{0.5} \mathrm{Si}_{0.5} / \mathrm{Ge}_{x} \mathrm{Si}_{1-x} / \mathrm{Si}(001)$, any change in the magnitude or sign of the strain can change the surface energies and thus can influence the growth mode. The present paper will evidence the role played by the surface energy when comparing the 2D-3D growth mode transitions and the surface morphologies for $2 \%$ mismatched $\mathrm{In}_{x} \mathrm{Ga}_{1-x}$ As films grown on $\mathrm{InP}(001)$ by molecular-beam epitaxy (MBE) in different situations: (i) either in compression, viz., $x=0.82$ or in tension, viz., $x=0.25$; (ii) either non-intentionally-doped (nid) or highly doped; and (iii) surfaces either As stabilized or cation stabilized during growth. Experiments were done using reflection high-energy electron diffraction (RHEED) and an ultrahigh-vacuum scanning tunneling microscope (STM).

The samples were grown in a Riber 2300 reactor on wellsmoothed $\operatorname{In}_{0.53} \mathrm{Ga}_{0.47} \mathrm{As}$ buffers $(4000 \AA$ ) lattice matched to InP(001). The experimental growth conditions as well as the main experimental RHEED results are summarized in Table I. Bragg spot intensities measured during $\mathrm{MBE}$ growth for As-stabilized $\operatorname{In}_{0.82} \mathrm{Ga}_{0.18} \mathrm{As}$ and $\mathrm{In}_{0.25} \mathrm{Ga}_{0.75} \mathrm{As}$ films using near-equilibrium and far-from-equilibrium growth conditions are shown in Fig. 1 . In Table I and Fig. $1, r_{3 \mathrm{D}}$ and $H_{3 \mathrm{D}}$ refer to the critical thickness for the roughening growth mode (weak 2D-3D transition) and for the strong 2D-3D growth mode transition, respectively. The STM experiments were performed using a Besocke-Beetle ultrahigh-vacuum STM connected to the MBE chamber. ${ }^{9}$ Figure 2 shows characteristic images of As-stabilized $\operatorname{In}_{0.82} \mathrm{Ga}_{0.18} \mathrm{As}$ and $\mathrm{In}_{0.25} \mathrm{Ga}_{0.75} \mathrm{As}$ strained layers 5 and $13 \mathrm{ML}$ thick, respectively, i.e., just above the corresponding $H_{3 \mathrm{D}}$ transition. Typical cross sections along the [110] direction are also shown. These STM images are representative of the whole surface, and were obtained with a tunneling current of 0.2 $\mathrm{nA}$ and a tunneling voltage of $2 \mathrm{~V}$ applied to the sample. ${ }^{10}$

Let us now present and discuss the main RHEED and STM experimental results.

(i) For As-stabilized compressive $\operatorname{In}_{0.82} \mathrm{Ga}_{0.18} \mathrm{As}$, the $H_{3 \mathrm{D}}$ transition that appears around $22 \mathrm{ML}$ with standard growth conditions [Fig. 1(b)], is reduced to $5 \mathrm{ML}$ with nearequilibrium growth conditions [Fig. 1(a)]. In contrast, for As-stabilized tensile $\operatorname{In}_{0.25} \mathrm{Ga}_{0.75} \mathrm{As}$, the $H_{3 \mathrm{D}}$ onset is only slightly reduced from $14 \mathrm{ML}$ with far-from-equilibrium growth conditions [Fig. 1(d)] to $10.5 \mathrm{ML}$ with nearequilibrium growth conditions [Fig. 1(c)]. In the compressive case [Fig. 1(a)], the RHEED Bragg spot intensity remains perfectly constant below the $H_{3 \mathrm{D}}$ threshold, indicating true or quasitrue $2 \mathrm{D}$ growth mode as checked by STM. ${ }^{10}$ In contrast, in the tensile case [Fig. 1(c)], a weak and continuous increasing of the RHEED Bragg spot intensity is observed, starting from the early stages of growth beyond a threshold labeled $r_{3 \mathrm{D}}$. This phenomenon is associated to an increasing roughening of the surface before the onset of the 3D growth mode. Before and after the 2D-3D transition, a strong $(2 \times 4)$ RHEED pattern is always observed for As-stabilized $\mathrm{In}_{0.82} \mathrm{Ga}_{0.18} \mathrm{As}$, even stronger than for lattice-matched Asstabilized $\mathrm{In}_{0.53} \mathrm{Ga}_{0.47} \mathrm{As}$, whereas no reconstruction is observed for As-stabilized $\operatorname{In}_{0.25} \mathrm{Ga}_{0.75}$ As.

(ii) STM measurements just beyond $H_{3 \mathrm{D}}$ (Fig. 2), clearly show the growth of highly anisotropic, 5-10 ML high 3D platelets, elongated in the [110] direction for both Asstabilized $\operatorname{In}_{0.82} \mathrm{Ga}_{0.18} \mathrm{As}$ and As-stabilized $\mathrm{In}_{0.25} \mathrm{Ga}_{0.75} \mathrm{As}$. The platelet mean width in the [110] direction is equal to 250 $\AA$ for As-stabilized $\mathrm{In}_{0.82} \mathrm{Ga}_{0.18}$ As but only equal to $150 \AA$ for As-stabilized $\mathrm{In}_{0.25} \mathrm{Ga}_{0.75}$ As. Island cross sections reveal 
TABLE I. 2D-3D critical thicknesses $\left(H_{3 \mathrm{D}}\right)$ and roughness critical thicknesses $\left(r_{3 \mathrm{D}}\right)$ in monolayers $(\mathrm{ML})$, and RHEED surface reconstructions as a function of the experimental growth conditions: growth temperature $\left({ }^{\circ} \mathrm{C}\right)$, growth rate $\left(\mathrm{ML} \mathrm{s}{ }^{-1}\right)$, V/III beam-equivalentpressure (BEP) ratio, for $2 \%$ mismatched $\operatorname{In}_{x} \mathrm{Ga}_{1-x}$ As layers on $\operatorname{InP}(001)$ near equilibrium and far from equilibrium.

\begin{tabular}{|c|c|c|c|c|c|c|c|}
\hline \multirow{2}{*}{\multicolumn{2}{|c|}{$\begin{array}{l}\text { Growth conditions } \\
T=525^{\circ}\end{array}$}} & \multirow[b]{2}{*}{ Doping } & \multirow[b]{2}{*}{$\begin{array}{c}\text { Surface } \\
\text { stabilization }\end{array}$} & \multicolumn{2}{|c|}{$\begin{array}{l}\text { Compression } \\
\mathrm{In}_{0.82} \mathrm{Ga}_{0.18} \mathrm{As}\end{array}$} & \multicolumn{2}{|c|}{$\begin{array}{c}\text { Tension } \\
\operatorname{In}_{0.25} \mathrm{Ga}_{0.75} \mathrm{As}\end{array}$} \\
\hline & & & & $\begin{array}{l}\text { 2D-3D critical } \\
\text { thickness } \\
(\mathrm{ML})\end{array}$ & $\begin{array}{c}\text { RHEED } \\
\text { surface } \\
\text { reconstruction }\end{array}$ & $\begin{array}{l}\text { 2D-3D critical } \\
\text { thickness } \\
(\mathrm{ML})\end{array}$ & $\begin{array}{c}\text { RHEED } \\
\text { surface } \\
\text { reconstruction }\end{array}$ \\
\hline \multirow[t]{3}{*}{$\begin{array}{c}\text { Near } \\
\text { equilibrium }\end{array}$} & $\begin{array}{c}\mathrm{V} / \mathrm{III} \mathrm{BEP}=70 \\
0.22 \mathrm{ML} \mathrm{s}^{-1}\end{array}$ & NID & As & $H_{3 \mathrm{D}}=5$ & $\begin{array}{l}\text { strong } \\
(2 \times 4)\end{array}$ & $\begin{array}{l}r_{3 \mathrm{D}}=1-2 \\
H_{3 \mathrm{D}}=10.5\end{array}$ & no \\
\hline & & $5 \times 10^{18} \mathrm{~cm}^{-3}$ & As & $H_{3 \mathrm{D}}=3.5$ & no & $\begin{array}{l}r_{3 \mathrm{D}}=1-2 \\
H_{3 \mathrm{D}}=10.5\end{array}$ & no \\
\hline & $\begin{array}{c}\mathrm{V} / \mathrm{III} \mathrm{BEP}=5 \\
0.22 \mathrm{ML} \mathrm{s}^{-1}\end{array}$ & NID & cation & no & $\begin{array}{l}\text { strong } \\
(4 \times 2)\end{array}$ & no & $\begin{array}{l}\text { strong } \\
(4 \times 2)\end{array}$ \\
\hline \multirow[t]{3}{*}{$\begin{array}{l}\text { Far from } \\
\text { equilibrium }\end{array}$} & $\begin{array}{c}\mathrm{V} / \mathrm{III} \mathrm{BEP}=20 \\
0.66 \mathrm{ML} \mathrm{s}^{-1}\end{array}$ & NID & As & $H_{3 \mathrm{D}}=22$ & $\begin{array}{l}\text { strong } \\
(2 \times 4)\end{array}$ & $\begin{aligned} r_{3 \mathrm{D}} & =2 \\
H_{3 \mathrm{D}} & =14\end{aligned}$ & no \\
\hline & & $5 \times 10^{18} \mathrm{~cm}^{-3}$ & As & $H_{3 \mathrm{D}}=5.5$ & no & $\begin{aligned} r_{3 \mathrm{D}} & =2 \\
H_{3 \mathrm{D}} & =14\end{aligned}$ & no \\
\hline & $\begin{array}{c}\mathrm{V} / \mathrm{III} \mathrm{BEP}=5 \\
0.66 \mathrm{ML} \mathrm{s}^{-1}\end{array}$ & NID & cation & no & $\begin{array}{l}\text { strong } \\
(4 \times 2)\end{array}$ & no & $\begin{array}{l}\text { strong } \\
(4 \times 2)\end{array}$ \\
\hline
\end{tabular}

that a major part of the surface is formed by flat (001) planes (island tops and valley bottoms) that represent about $70 \%$ and $50 \%$ of the whole surface for As-stabilized $\mathrm{In}_{0.82} \mathrm{Ga}_{0.18} \mathrm{As}$ and As-stabilized $\mathrm{In}_{0.25} \mathrm{Ga}_{0.75} \mathrm{As}$, respectively. In both cases, the side facets form an angle of $17.4^{\circ}$ relative to the (001) plane, i.e., close to $19.5^{\circ}$ of the (114) plane orientation. $1,11,12$

(iii) In compression, for both near-equilibrium and farfrom-equilibrium growth conditions, the critical thickness $H_{3 \mathrm{D}}$ for As-stabilized layers is strongly reduced from undoped to highly doped samples. In contrast, no difference is observed in tension. This has to be associated to the quality of the RHEED patterns which appear to be different between
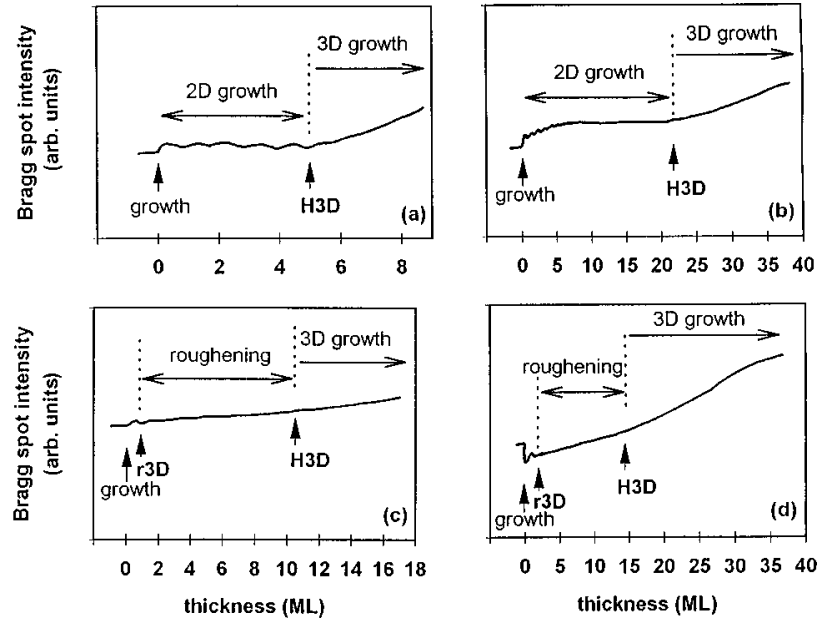

FIG. 1. Bragg spot intensity measured during the growth of As-stabilized (a) $\mathrm{In}_{0.82} \mathrm{Ga}_{0.18}$ As using near-equilibrium growth conditions, (b) $\mathrm{In}_{0.82} \mathrm{Ga}_{0.18}$ As using far-from-equilibrium growth conditions, (c) $\mathrm{In}_{0.25} \mathrm{Ga}_{0.75}$ As using near-equilibrium growth conditions, and (d) $\mathrm{In}_{0.25} \mathrm{Ga}_{0.75} \mathrm{As}$ using far-from-equilibrium growth conditions. $H_{3 \mathrm{D}}$ and $r_{3 \mathrm{D}}$ indicate the onsets of the 3D growth and of the rough growth, respectively. highly doped and undoped layers in compression whereas no difference is observed in tension.

(iv) Changing the surface reconstruction from $(2 \times 4)$ Asstabilization to $(4 \times 2)$ cation stabilization prevents the $3 \mathrm{D}$ growth mode appearing both for tension and compression. With cation-stabilized growth conditions, a strong $(4 \times 2)$ RHEED reconstruction is observed both for compression and tension.

The earliest model that has been evoked to justify a 3D morphology for strained films is the Asaro-Tiller-Grinfeld instability model, ${ }^{13}$ which predicts that surface undulations

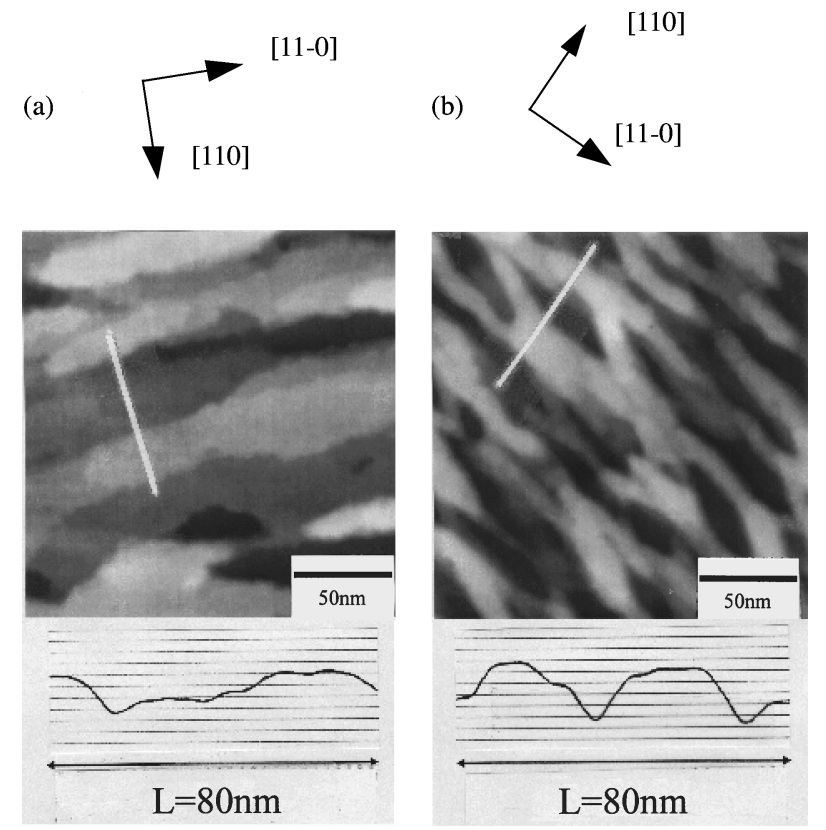

FIG. 2. STM images of As-stabilized $\operatorname{In}_{0.82} \mathrm{Ga}_{0.18} \mathrm{As}$ (a) and $\mathrm{In}_{0.25} \mathrm{Ga}_{0.75} \mathrm{As}$ (b) strained layers 5 and $13 \mathrm{ML}$ thick, respectively, and corresponding cross sections. Distance between two horizontal lines of the cross section is $5 \AA$. 
can reduce the total energy. However, this continuous model, useful to predict the precursor 2D surface undulations, cannot be invoked when a 2D-3D growth mode transition occurs because it does not take into account the crystal structure and thus the orientation dependence of surface energies. A more recent way ${ }^{6,7}$ to predict the $2 \mathrm{D}-3 \mathrm{D}$ growth mode transition is to compare the total energy $E_{T}$ defined as bulk strain energy $E_{B}$ plus surface energy $E_{S}$, for the two competing $2 \mathrm{D}$ and 3D processes: the transition arises when the final 3D state has a total energy $E_{T}^{f}=E_{B}^{f}+E_{S}^{f}$ smaller than that $E_{T}^{i}=E_{B}^{i}$ $+E_{S}^{i}$ of the initial 2D state, taking into account that $E_{B}^{f}$ $<E_{B}^{i}$, and $E_{S}^{f}>E_{S}^{i}$. At this stage, it is worth noting that the smaller $E_{S}^{f}-E_{S}^{i}$ is, the smaller the 2D-3D critical thickness will be and that $E_{s}^{f}$ includes contributions both from platelets and facets.

The strain energy density per bulk unit cell in $\operatorname{In}_{x} \mathrm{Ga}_{1-x} \mathrm{As}$ may be calculated from the usual Matthews relationship. ${ }^{14}$ We found $E_{B}=0.198 \mathrm{meV}$ per $\AA^{3}$ for $\operatorname{In}_{0.82} \mathrm{Ga}_{0.18} \mathrm{As}$ and $E_{B}$ $=0.259 \mathrm{meV}$ per $\AA^{3}$ for $\operatorname{In}_{0.25} \mathrm{Ga}_{0.75} \mathrm{As}$. On the other hand, the surface energy per surface unit cell is strongly dependent on the reconstructions allowed for the (001) face at a given As coverage $\theta_{\mathrm{As}}$. The $\mathrm{In}_{x} \mathrm{Ga}_{1-x} \mathrm{As}(001)$ surface energies are not known; however, relative trends can be predicted using data and results for GaAs surface reconstructions that have been extensively studied. ${ }^{15-18}$ For As-stabilized GaAs(001), it has been shown ${ }^{15}$ that the surface energy is strongly reduced from $42.7 \mathrm{meV}$ per $\AA^{2}$ for the As-rich unreconstructed surface $\left(\theta_{\mathrm{AS}}=1\right)$ to $21 \mathrm{meV}$ per $\AA^{2}$ for the $(2 \times 4)$ reconstruction $\left(\theta_{\mathrm{AS}}=0.75\right)$. Thus, for a few ML coverage, the surface-energy term is about ten times higher than the bulk elastic energy and so a slight variation in surface energy should strongly modify the 2D-3D energy balance. This may explain the observed differences between the compression and tension cases since strain may influence the surface energy as follows: In the $(2 \times 4)$ reconstruction, the As-As dimers are lying above the ideal lattice position by +0.29 $\AA$ due to bond relaxation. ${ }^{15}$ Considering that the mismatchinduced lattice distortion naturally moves up for compressively strained $\operatorname{In}_{0.82} \mathrm{Ga}_{0.18}$ As on InP and down for tensilely strained $\mathrm{In}_{0.25} \mathrm{Ga}_{0.75} \mathrm{As}$ on InP, it appears that the surface is better stabilized for compressively strained $\mathrm{In}_{0.82} \mathrm{Ga}_{0.18} \mathrm{As}$ on $\mathrm{InP}$ than for lattice-matched $\mathrm{In}_{0.53} \mathrm{Ga}_{0.47}$ As. For the tensilely strained $\operatorname{In}_{0.25} \mathrm{Ga}_{0.75} \mathrm{As}$ on InP, the bond distortion is too great for As dimers to be well stabilized. This favors some disorder and should prevent the $(2 \times 4)$ reconstruction from being well established. Local order should involve As dimers and differences occur only in the amount of long-range disorder that is greater for tension than for compression. This explains the differences in the quality of the reconstruction pattern observed by RHEED (Table I) for As-stabilized $\mathrm{In}_{x} \mathrm{Ga}_{1-x}$ As layers: a strong $(2 \times 4)$ pattern for compression, a weak $(2 \times 1)$ pattern for lattice matched layers, and no reconstruction for tension. This behavior corresponds to an increase in surface energy from compression to tension.

Beyond the 2D-3D growth mode transition, the 3D morphology (Fig. 2) for both compression and tension is characterized by platelets and valleys made of (001) and (114) planes but with a different size and distributions (see Fig. 2). The similarity between tension and compression 3D morphologies allows us to consider that bulk energies $E_{B}^{f}$ should be slightly identical in compression and tension. On this basis, the differences in 3D onset observed between compression and tension are explained as follows: the strong (2 $\times 4$ ) reconstruction in compression (low $E_{S}^{i}$ ) keeps the surface from roughening until the appearance of a clear 3D growth mode onset because the surface energy in the 3D final state is much higher due to the presence of the (114) facets $\left(E_{S}^{f}-E_{S}^{i}\right.$ is large). Conversely, the breaking of the reconstruction in tension allows roughening of the surface even at the early growth stages $\left(r_{3 \mathrm{D}}\right)$. This can be understood because the energy of a disordered 2D surface is high and close to that of a rough surface $\left(E_{S}^{f}-E_{S}^{i}\right.$ is small). In fact, the presence of many single steps as on a rough surface implies also a breaking of the $(2 \times 4)$ reconstruction. In this case, the roughening thus allowed permits, in its turn, the strain energy to be partially relaxed and consequently delays the formation of large islands $\left(H_{3 \mathrm{D}}\right)$ unlike the compressive case. As discussed above, the surface energy of tensilely strained $\operatorname{In}_{x} \mathrm{Ga}_{1-x}$ As is higher than that of the corresponding relaxed material. This suggests that this effect could be the reason for the formation of small islands that relax strain more efficiently than larger ones. In compression, island tops tend to be as large and as flat as possible to preserve the best long-range order for the initial strong $(2 \times 4)$ reconstruction. Note that our explanation (surface modification) about the origin of the difference of surface roughness between compression and tension is similar to that given by Tersoff. ${ }^{7}$ However, there is no discrepancy with the arguments of Xie et $a l^{8}{ }^{8}$ since changes in surface energy through roughness are directly related to the number and the type of the existing steps. The difference observed between our $\mathrm{Ga}_{x} \mathrm{In}_{1-x} \mathrm{As}$ surface (tensile layer rougher than compressive layer) and the Xie et al. SiGe surface (compressive layer rougher than tensile layer) arise probably because the III-V zinc-blende semiconductor involves two kinds of atoms (anions plus cations) whereas diamondlike compounds involve only one.

The role of surface reconstruction effects has been confirmed by experimental results obtained for highly doped Asstabilized samples. Doping is known to weaken the reconstruction long-range order: the surface generally presents domain boundaries between well-reconstructed regions, ${ }^{18}$ which increases the surface energy. In compression, the 2D-3D growth mode onset occurs earlier for highly doped samples than for unintentionally doped samples due to reduced $E_{S}^{f}-E_{S}^{i}$. In tension, since no reconstruction is detected by RHEED, doping cannot affect strongly the surface reconstruction nor the surface energy and thus the 2D-3D growth-mode-transition onset is not doping dependent since $E_{S}^{f}-E_{S}^{i}$ remains constant.

No 2D-3D transition is observed for the cation-stabilized growth mode either for compression or for tension. The hierarchy between surface tensions versus surface orientation ${ }^{17}$ allows in some cases a facetting of the initial (001) face into (111) facets, and thus into (114) $A$ facets made in our case from (001) plus (111) $A$ planes (as double $A$ steps). For $\operatorname{GaAs}(001)$, the cation-rich $(4 \times 2)$ reconstructed (001) surfaces are known to have a higher surface energy (38.4 meV per $\left.\AA^{2}\right)$ than the $(2 \times 4)$ As-stabilized (001) ones $\left(21 \mathrm{meV}\right.$ per $\left.\AA^{2}\right) .{ }^{15}$ For $\operatorname{GaAs}(111) A$, the surface energy is 58.4-68.9 meV per $\AA^{2}$ for the As-stabilized (111)A surface 
orientation but $134.6-144.4 \mathrm{meV}$ per $\AA^{2}$ for the Gastabilized (111)A surface orientation. ${ }^{17}$ This suggests that In-rich (114) $A$ facets made of In-rich (001) and (111) $A$ planes should have a very high surface energy and consequently a low probability to exist. In contrast, As-rich (114) $A$ facets have a lower surface energy. This explains why a $2 \mathrm{D}-3 \mathrm{D}$ growth mode transition occurs in As-rich conditions and not in In-rich conditions (large $E_{S}^{f}-E_{S}^{i}$ ).

In summary, we have shown that when minimizing kinetic effects by using near-equilibrium growth conditions, the surface energy through surface reconstructions can be a preponderant parameter in determining the onset of the 2D-3D growth mode transition and the resulting 3D morphology. Because the As-terminated (001) surface may be strongly stabilized if reconstructed by surface dimers, any effect that modifies the long-range ordering of this reconstruction (as doping may do) or its efficiency (as strain may do) will affect the 2D-3D growth-mode-transition onset, all thing being equal in the final state. However, in tension, the breaking of the surface reconstruction allows a roughening of the surface that partially relaxes the strain energy and thus delays the strong 2D-3D growth mode transition. On the other hand, changing growth conditions, from As stabilization to cation stabilization, prevent a $3 \mathrm{D}$ growth mode because facetting of the (001) face into (114)A plans is energetically allowed only if the surface is As stabilized during growth.

The authors are grateful to Catherine Priester for many helpful discussions.
${ }^{1}$ G. J. Whaley and P. I. Cohen, in Layered Structures: Heteroepitaxy, Superlattices, Strain, and Metastability, edited by B. W. Dodson, L. W. Showalter, J. E. Cunningham, and F. H. Pollak, MRS Symposia Proceedings No. 160 (Materials Research Society, Pittsburgh, 1990), p. 35; Appl. Phys. Lett. 57, 144 (1990).

${ }^{2}$ C. W. Snyder et al., Appl. Phys. Lett. 66, 3032 (1991); C. W. Snyder, J. M. Manfield, and B. G. Orr, Phys. Rev. B 46, 9551 (1992); C. W. Snyder, H. Muneka, and B. G. Orr, Appl. Phys. Lett. 62, 46 (1993); C. W. Snyder and B. G. Orr, ibid. 62, 46 (1993).

${ }^{3}$ N. Grandjean, J. Massies, and V. H. Etgens, Phys. Rev. Lett. 69, 796 (1992).

${ }^{4}$ B. J. Orr et al., Europhys. Lett. 19, 33 (1992).

${ }^{5}$ J. Tersoff and R. M. Tromp, Phys. Rev. Lett. 70, 2782 (1993); J.

Tersoff and F. K. LeGoues, ibid. 72, 3570 (1994).

${ }^{6}$ C. Priester and M. Lannoo, Phys. Rev. Lett. 75, 93 (1995).

${ }^{7}$ J. Tersoff, Phys. Rev. Lett. 74, 4962 (1995).

${ }^{8}$ Y. H. Xie et al., Phys. Rev. Lett. 73, 3006 (1994); 74, 4963 (1995).
${ }^{9}$ P. Krapf, J. P. Lainé, Y. Robach, and L. Porte, J. Phys. III 5, 1871 (1995).

${ }^{10}$ L. Porte et al., Surf. Sci. 352/354, 60 (1996); P. Krapf, Y. Robach, M. Gendry, and L. Porte, Phys. Rev. B 55, 10229 (1997).

${ }^{11}$ G. Hollinger et al., Appl. Phys. Lett. 57, 144 (1992).

${ }^{12}$ A. Ponchet et al., J. Cryst. Growth 153, 71 (1995).

${ }^{13}$ X. Asaro and Y. Tiller, Metall. Trans. 13, 1789 (1972); M. A. Grinfeld, J. Intell. Mater. Syst. Struct. 4, 76 (1993).

${ }^{14}$ J. W. Matthews, J. Vac. Sci. Technol. 12, 126 (1975).

${ }^{15}$ Guo-Xin Qian, R. M. Martin, and D. J. Chadi, Phys. Rev. B 37, 1303 (1988); 38, 7649 (1988); Phys. Rev. Lett. 60, 19 (1988).

${ }^{16}$ E. Kaxiras et al., Phys. Rev. B 35, 9625 (1987); 35, 9636 (1987).

${ }^{17}$ N. Chetty and R. M. Martin, Phys. Rev. B 45, 6089 (1992).

${ }^{18}$ M. D. Pashley, Phys. Rev. B 40, 10481 (1989); M. D. Pashley, K. W. Haberern, and R. M. Feenstra, J. Vac. Sci. Technol. B 10, 1874 (1992); M. D. Pashley and K. W. Haberen, Ultramicroscopy 42, 1281 (1992). 